\title{
Jarak Minimum Orbit dan Tumbukan Populasi Asteroid dekat-Bumi dengan Planet Bumi
}

\author{
Annisa Nur'imani Fauziah ${ }^{1}$, Judhistira Aria Utama ${ }^{1}$, Ferry M. Simatupang ${ }^{2}$ \\ ${ }^{1}$ Physics Education Department, Universitas Pendidikan Indonesia, \\ Jl. Dr. Setiabudhi 229, Bandung, 40154, Indonesia \\ ${ }^{2}$ Kelompok Keilmuan Astronomi, Institut Teknologi Bandung, \\ Jl. Ganesha 10, Bandung, 40132, Indonesia
}

Penulis Penanggungjawab.E-mail: annisafauziah@student.upi.edu

\begin{abstract}
ABSTRAK
Asteroid dekat-Bumi diketahui memiliki orbit yang kaotik akibat seringnya terjadi papasan dekat dengan planet-planet terestrial. Orbit yang kaotik dapat membuat populasi objek ini berakhir sebagai penumbuk matahari maupun planet-planet. Dalam penelitian ini digunakan 3372 sampel asteroid dekat-Bumi nyata dengan orbit yang dikenal baik $(U=0)$. Evolusi orbit sampel dilakukan dengan memanfaatkan paket integrator Swift_RMVS4 menggunakan model Tata Surya yang terdiri atas Matahari dan kedelapan planet termasuk Bulan sebagai objek terpisah. Propagasi orbit di bawah pengaruh gravitasi dilakukan hingga kurun $2 \times 10^{6}$ tahun ke depan dengan langkah waktu komputasi $10^{-3}$ tahun ( $\sim 9$ jam). Hingga akhir komputasi diperoleh fluks masuk sampel populasi asteroid dekat-Bumi yang berakhir di zona pembuangan (menumbuk Matahari, terlempar keluar Tata Surya, dan menumbuk planet-planet) adalah sebesar $14 \pm 2$ asteroid per juta tahun untuk $\mathrm{H}<18$ (bersesuaian dengan diameter asteroid 0,67 km - 1,5 km). Berdasarkan informasi jarak minimum orbit (Minimum Orbit Intersection Distance - MOID) seluruh sampel dengan planet Bumi dengan perhitungan berdasarkan geometri, diperoleh nilai kebolehjadian tumbukan intrinsik $\left(P_{i}\right)$ sebesar $1,099 \times 10^{-15}$ per $\mathrm{km}^{2}$ per tahun per objek yang bersesuaian dengan kejadian satu tumbukan dengan planet Bumi setiap 10 juta tahun. Frekuensi tumbukan yang diperoleh ini lebih singkat daripada yang disimpulkan dari penelitian terdahulu. Penggunaan sampel yang lebih banyak dan dengan kualitas orbit yang lebih baik diduga kuat menjadi faktor penyebab perbedaan.
\end{abstract}

Kata Kunci : Asteroid Dekat-Bumi; Laju Peluruhan Fraksional, Laju Tumbukan, MOID. 


\begin{abstract}
Near-Earth Asteroids had been known for their chaotic orbits due to frequent close-encounter with Terrestrial planets. These chaotic orbits responsible to their final fate as planets impactor. Within this work, sample of as many as 3,372 real Near-Earth Asteroids with high quaity orbit $(U=0)$ have been used. The Swift_RMVS4 integrator package accomodating the Solar System model consists of all planets and treated the Moon as a separated object was employed. Asteroids' orbit computation was run for $2 \times 10^{6}$ years forward with $10^{-3}$ years ( $\sim 9$ hours) timestep and only gravitational force was considered. By the end of computation we found the entrance flux from near-Earth region into sinks (collide the Sun or planets and ejected from the Solar System) as many as $14 \pm 2$ asteroids per million years for $\mathrm{H}<18$ (asteroid's diameter $0.67 \mathrm{~km}-1,5 \mathrm{~km}$ ). Based on computed asteroid's minimum orbit distance (Minimum Orbit Intersection Distance - MOID), the intrinsic collision probability $\left(P_{i}\right)$ is $1.099 \times 10^{-15}$ per $\mathrm{km}^{2}$ per year per asteroid which correspond to one impact on Earth every $10^{7}$ years. This value is lower than previously predicted by other researchers. The use of larger sample with high quality orbits within our work are suspected as the causative difference.
\end{abstract}

Keywords : Near-Earth Asteroids; Fractional Decay Rate; Collision Rate; MOID.

\section{Pendahuluan}

Kumpulan asteroid yang berada di antara orbit planet Mars dan Jupiter, yang disebut sebagai asteroid Sabuk Utama (main belt), dapat mengalami peralihan orbit menjadi objek yang berada di kawasan dekat-Bumi. Melalui mekanisme, di antaranya tumbukan antar-asteroid di Sabuk Utama yang terjadi dengan arah lontaran yang tepat dan dengan kecepatan lontar yang cukup besar [1], fragmen-fragmen hasil tumbukan dapat memasuki daerah resonansi gerak rata-rata (mean-motion resonance) maupun resonansi sekular (secular resonance) yang mampu membuat orbit objek ini menjadi memotong orbit planet Mars [2]. Selanjutnya, interaksi gravitasi dengan planet Mars memegang peranan penting dalam mengantarkan fragmen-fragmen hasil tumbukan tersebut memasuki kawasan bagian dalam Tata Surya membentuk populasi baru, yaitu populasi asteroid dekat-Bumi. Secara definisi, ruang dekat-Bumi merupakan kawasan 
yang memenuhi ketidaksamaan nilai $q$ (jarak perihelion) $<1,3$ sa \& nilai $Q$ (jarak aphelion) $>0,98$ sa $[1$ sa (satuan astronomi) didefinisikan sebagai jarak rata-rata Bumi Matahari yang bernilai $\left.1,5 \times 10^{8} \mathrm{~km}\right]$.

Populasi asteroid yang berada di ruang dekat-Bumi tersebut dapat dikelompokkan ke dalam empat kelas utama berdasarkan karakteristik orbitnya. Keempat kelas asteroid dekat-Bumi tersebut adalah Amor [ $a$ (setengah sumbu panjang orbit elips) $>1$ sa dan $1,017 \mathrm{sa}<q<1,3 \mathrm{sa}$ ], Apollo $(a>1,0 \mathrm{sa}$ dan $q<1,017 \mathrm{sa}$ ), Aten $(a<1,0$ sa dan $Q>$ 0,983 sa), dan Atira ( $a<1$ sa dan $Q<0,983$ sa). Dengan karakteristik orbit yang demikian, kelas Amor merupakan kelompok asteroid dekat-Bumi yang memiliki orbit memotong orbit planet Mars, Apollo dan Aten memotong orbit Bumi, sementara kelas Atira seluruh orbitnya berada di sebelah dalam orbit Bumi.

Papasan dekat (close encounter) yang dialami populasi asteroid dekat-Bumi dengan planet-planet Terestrial (Merkurius hingga Mars) berpengaruh dominan terhadap dinamika di ruang dekat-Bumi. Bahkan bukan saja peran dari papasan dekat, melainkan juga andil dari dinamika resonansi yang mempengaruhi peluruhan populasi asteroid dekat-Bumi ke zona pembuangan [3]. Bottke dkk. (2002)[4] membagi zona pembuangan menjadi zona mayor dan minor berdasarkan besar-kecilnya contributing dalam mengurangi populasi asteroid dekat-Bumi. Kondisi akhir asteroid sebagai penumbuk Matahari maupun terlempar keluar dari Tata Surya (> 60\%) telah diketahui mendominasi keluaran komputasi numerik, dibandingkan dengan keadaan akhir sebagai penumbuk planetplanet $(<20 \%)$ [5].

Hasil yang diperoleh Gladman dkk. (1997) dan Morbidelli \& Gladman (1998) [5], menyimpulkan hanya $1 \%$ dari populasi asteroid dekat-Bumi yang berakhir sebagai penumbuk planet Bumi. Bukti tumbukan antara asteroid dan komet dengan planet Bumi pada masa lalu terekam dalam sejarah geologi planet ini melalui kehadiran kawah-kawah besar dan analisis kandungan iridium [6]. Bahkan peristiwa tumbukan antara Bumi dengan asteroid bergaris tengah beberapa meter hingga beberapa puluh meter masih terjadi di era modern ini, seperti yang dialami Bumi dan asteroid 2008 TC3 [7] maupun dengan "asteroid Chelyabinsk" $[8,9]$.

Berangkat dari uraian singkat di atas, penelitian ini bertujuan untuk memperoleh frekuensi tumbukan antara populasi asteroid dekat-Bumi dari seluruh kelas taksonomi yang telah diketahui hingga saat ini dengan planet Bumi melalui simulasi numerik yang menerapkan metode baru dalam perhitungan jarak minimum orbit (Minimum Orbit Intersection Distance MOID) untuk sebarang pasangan orbit heliosentrik [10]. 


\section{Metode}

Simulasi numerik dalam bentuk masalah N-benda (N-body problem) telah digunakan dalam penelitian ini. Komputasi orbit atas sampel data asteroid dekat-Bumi yang diperoleh dari laman http://ssd.jpl.nasa.gov/sbdbquery.cgi dilakukan meng-gunakan paket integrator Swift_RMVS4 yang merupakan versi terakhir dari paket Swift yang dikembangkan Levison \& Duncan (1994). Algoritma Regularized Mixed-Variable Symplectic (RMVS) dalam paket integrator Swift memperbaiki metode Mixed-Variable Symplectic (MVS) [11]. Regularisasi dalam algoritma ini merupakan sebuah proses matematika yang bertujuan menghilangkan singularitas dari persamaan gerak benda (dalam bentuk persamaan diferensial) yang hendak dipecahkan. Varian algoritma RMVS4 yang digunakan dalam penelitian ini merupakan versi yang mampu menghitung peristiwa papasan dekat antara asteroid dengan planet-planet secara lebih teliti.

Proses seleksi yang hanya menyertakan asteroid dekat-Bumi dari keempat kelas (Amor, Apollo, Aten, dan Atira), baik yang sudah bernomor maupun belum dengan orbit yang telah diketahui dengan sangat baik (condition code $\mathrm{U}=0$; bersesuaian dengan batas galat orbit kurang dari 1"/dekade), telah berhasil diperoleh sebanyak 3372 sampel asteroid. Keterbatasan paket integrator untuk melakukan integrasi orbit 3372 sampel asteroid secara sekaligus, sehingga membuat penelititian ini harus melakukan pemecahan jumlah. Untuk mengatasinya, 3372 sampel asteroid yang disusun berdasarkan radius (dari terkecil hingga terbesar) dipecah ke dalam empat kelompok (batch), dengan pengaturan batch1 sampai dengan batch 3 masing-masing terdiri atas 1000 asteroid dan batch 4 terdiri atas 372 asteroid.

Proses komputasi dijalankan dengan memanfaatkan fasilitas PC (Processor Intel(R) Core(TM) i3-3240T CPU@2,90 GHz, RAM 4,00 GB, 64 bit operating system) yang tersedia di Laboratorium Komputasi Departemen Pendidikan Fisika FPMIPA - Universitas Pendidikan Indonesia. Proses komputasi dijalankan hingga $2 \times 10^{6}$ tahun ke depan menggunakan model Tata Surya dengan 10 benda masif (Matahari dan kedelapan planet, Merkurius hingga Neptunus, serta Bulan yang diperlakukan sebagai benda mandiri). Setiap batch dijalankan untuk kelipatan $5 \times 10^{5}$ tahun, sehingga akan diperoleh hasil keluaran (output) komputasi batch1 hingga batch4 pada tiap kelipatan $5 \times 10^{5}$ tahun. Seluruh batch dijalankan dengan pengaturan yang sama, yaitu menggunakan langkah waktu (timestep) $10^{-3}$ tahun ( $\sim$ jam) dan hasil komputasi dicuplik setiap $10^{3}$ tahun. Jejak evolusi orbit sampel asteroid diikuti hingga ada yang tereliminasi karena 
menumbuk Matahari, terlempar menjauh dari Matahari hingga $a>100$ sa, atau mengalami tumbukan dengan planet-planet. Penelitian ini hanya menyertakan interaksi gravitasi dalam meninjau evolusi orbit asteroid melalui paket integrator yang digunakan. Interaksi gravitasi hanya terjadi antar-benda masif dan antar-benda masif dengan asteroid, namun tidak untuk antarasteroid yang dianggap sebagai benda tak bermassa.

Salah satu cara untuk memperoleh probabilitas tumbukan antara dua orbit heliosentrik adalah dengan mengestimasi nilai laju tumbukan $f$ (dalam satuan: tahun $^{-}$ 1) melalui tumbukan yang diamati secara langsung di dalam simulasi numerik selama waktu $t$. Hanya saja tumbukan antara asteroid dengan planet merupakan peristiwa yang jarang dijumpai dalam simulasi numerik, sehingga untuk menghindari problem "small number statistics" di dalam penelitian ini kejadian tumbukan diidentifikasi meng-gunakan kriteria MOID $<R_{c}$ (radius tangkapan gravitasi planet). Nilai $R_{c}$ dihitung dari:

$$
R_{c}=R_{\oplus} \sqrt{1+\left(\frac{v_{e s c}}{V_{\infty}}\right)^{2}}
$$

dengan $\mathrm{R}_{\oplus}$ menyatakan radius fisik Bumi, $V_{\text {esc }}$ kelajuan lepas di permukaan Bumi, dan $\mathrm{V}_{\infty}$ kelajuan asteroid saat saat berada di jarak yang jauh dari Bumi.
Penggunaan MOID untuk memperoleh kebolehjadian tumbukan dapat dijumpai dalam sejumlah literatur [12,13,14]. Perhitungan MOID dilakukan dengan memanfaatkan metode baru menggunakan prosedur numerik dan iteratif untuk sebarang pasangan orbit heliosentrik [10] . Penggunaan nilai MOID mengizinkan untuk menyertakan pula dua orbit heliosentrik yang tidak berpotongan, yang dalam metode konvensional dianggap memiliki nilai probabilitas tumbukan nol (0).

Untuk $N$ asteroid (proyektil) dan satu planet (target) tertentu, nilai kebolehjadian tumbukan intrinsik $P_{i}$ dapat diperoleh dari banyaknya MOID yang terjadi antara seluruh asteroid dengan planet tersebut (dinyatakan sebagai $M$ ) untuk suatu jarak yang kurang dari nilai tertentu $r$ selama selang waktu $t$ yang ditinjau [15], yaitu melalui persamaan:

$$
\mathrm{P}_{\mathrm{i}}=\frac{\mathrm{M}}{\mathrm{Ntr}^{2}}
$$

Sementara, laju tumbukan $f$ per asteroid dengan suatu planet dapat diperoleh dari informasi $P_{i}$ melalui hubungan:

$$
f=P_{i} R_{c}^{2}
$$




\section{Hasil dan Pembahasan}

Pada akhir proses komputasi, diperoleh sebanyak 21\% sampel asteroid telah berakhir dengan menuju zona pembuangan. Peluruhan jumlah populasi sampel ini ditunjukkan dalam Gambar 1 Proses peluruhan jumlah populasi yang terjadi dapat diperoleh dengan menggunakan fungsi eksponensial yang diperoleh bedasarkan grafik jumlah populasi sample sebagai fungsi waktu berikut:

$$
y=8,0999 \times e^{-\left(1 \times 10^{-5}\right) t}
$$

Dengan menggunakan Persamaan (4), maka dapat diperoleh waktu karakteristik yang membuat populasi sampel menjadi setengah kali jumlah semula (median dynamical lifetime; Gladman dkk., 2000), yaitu $9 \times 10^{6}$ tahun. Nilai yang diperoleh ini hampir 5 $\times$ lebih panjang daripada durasi integrasi yang telah dijalankan.

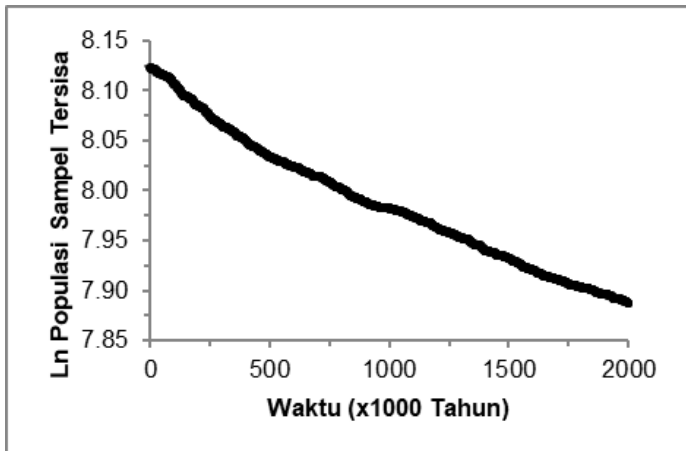

Gambar 1. Grafik laju peluruhan populasi sampel asteroid dekat-Bumi karena berakhir menuju zona pembuangan selama durasi komputasi $2 \times 10^{6}$ tahun.
Gambar 1 menunjukan bahwa grafik laju peluruhan populasi sampel asteroid dekat-Bumi karena berakhir menuju zona pembuangan selama durasi komputasi $2 \mathrm{x}$ $10^{6}$ tahun terjadi penurunan, hal tersebut dikarenakan pada penelitian ini sampel yang digunakan selama waktu komputasi merupakan sampel yang sama dengan meninjau sampel yang berakhir menuju zona pembuangan dan mengabaikan sampel yang masuk kedalam kawasan dekat-Bumi selama proses komputasi berlangsung.

Mengikuti prosedur Morais \& Morbidelli (2002) [16] dan Bottke dkk., (2002)[4], dengan menggunakan Persamaan (4) dalam bentuk logaritma natural maka dapat diperoleh nilai laju peluruhan fraksional populasi sampel perjuta tahun. Rajah nilai laju peluruhan fraksional terhadap waktu ditunjukkan dalam Gambar 2.

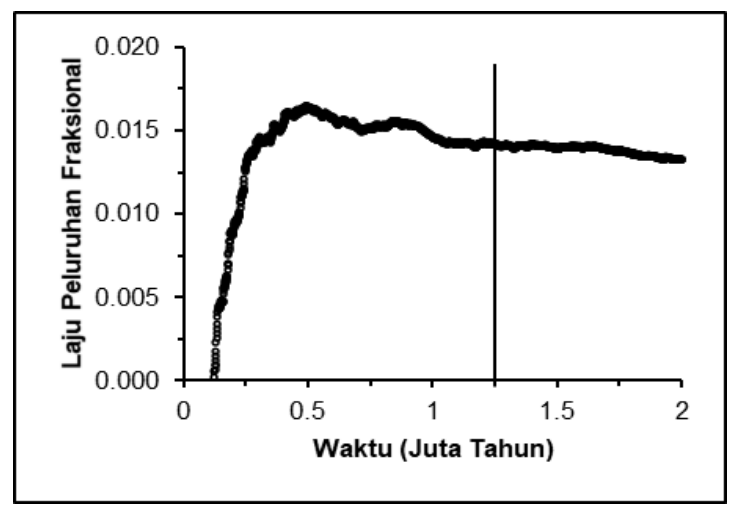

Gambar 2. Grafik laju peluruhan fraksional sebagai fungsi waktu. Dua garis vertikal menandai rentang waktu dengan nilai laju peluruhan fraksional yang stabil. 
Dengan melakukan analisis pada Gambar 2, diperoleh nilai laju peluruhan fraksional yang stabil pada rentang waktu $1,2 \times 10^{6}$ tahun sampai dengan $1,6 \times 10^{6}$ tahun. Telah dihitung nilai rata-rata laju peluruhan fraksional sampel asteroid menuju zona pembuangan hanya selama rentang waktu dengan nilai laju peluruhan fraksional yang stabil, yaitu sebesar $0,0141 \pm 9,703 \times 10^{-5}$ per juta tahun. Menggunakan model populasi keadaan tunak asteroid dekat-Bumi sebesar $960 \pm$ 120 asteroid untuk $H$ (magnitudo absolut) $<18$ (Bottke dkk., 2002)[4], selanjutnya dapat dihitung fluks masuk asteroid dari ruang dekat-Bumi menuju zona pembuangan dengan mengkalikan nilai rata-rata laju peluruhan fraksional sampel asteroid menuju zona pembuangan hanya selama rentang waktu dengan nilai laju peluruhan fraksional yang stabil dengan model populasi keadaan tunak asteroid dekat-Bumi, sehingga diperoleh fluks masuk asteroid dari ruang dekat-Bumi menuju zona pembuangan sebanyak $13,54 \pm 1,69$ atau sekitar $14 \pm 2$ asteroid yang hilang per juta tahun akibat berakhir di zona pembuangan.

Memperoleh probabilitas tumbukan antara dua orbit heliosentrik dengan mengestimasi nilai laju tumbukan $f$ (dalam satuan: tahun $^{-1}$ ) melalui tumbukan yang diamati secara langsung di dalam simulasi numerik selama waktu $t$. Di dalam penelitian ini kejadian tumbukan diidentifikasi meng-gunakan kriteria MOID $<R_{c}$ (radius tangkapan gravitasi planet). Dengan menggunakan Persamaan (1) maka diperoleh nilai $R_{c}$ sebesar $6,38 \mathrm{x}$ $10^{-05} \mathrm{au}$

Menggunakan Persamaan

diperoleh nilai $P_{i}$ sebesar $1,099 \times 10^{-15}$ per $\mathrm{km}^{2}$ per tahun, sementara dengan Persamaan (3) didapatkan nilai $f=1,007$ $\times 10^{-7}$ tumbukan per tahun. Kebalikan dari nilai $f$ menyatakan collisional lifetime, yaitu skala waktu sebuah proyektil bertumbukan dengan objek target tertentu. Dengan nilai $f$ yang telah diperoleh di atas, terjadi 1 tumbukan antara asteroid dengan Bumi dalam waktu $\sim 10^{7}$ tahun. Secara statistik, tumbukan antara populasi asteroid dekat-Bumi $(H<18)$ yang berjumlah 960 \pm 120 asteroid dengan planet Bumi, terjadi tiap $\sim 11.000$ tahun.

Nilai-tengah kala hidup sampel asteroid dekat-Bumi yang diperoleh dalam penelitian ini (9x10 $0^{6}$ tahun) dekat dengan yang diperoleh Gladman dkk. (2000)[5], yaitu $1 \times 10^{7}$ tahun. Penelitian ini dan pekerjaan yang dilakukan Gladman dkk. (2000) memiliki beberapa kemiripan, yaitu menggunakan paket integrator Swift (RMVS4/versi terakhir dalam penelitian ini dan RMVS3/versi sebelumnya dalam pekerjaan mereka) dan menggunakan sampel yang diseleksi berdasarkan kualitas orbit (3372 sampel dalam pekerjaan ini dan 117 sampel dalam pekerjaan mereka). Meskipun demikian, faktanya Gladman 
dkk. (2000) memperoleh laju tumbukan populasi asteroid dekat-Bumi dengan planet Bumi senilai 4,7 × $10^{-9}$ per tahun (bersesuaian dengan 1 tumbukan dalam $2,1 \times 10^{8}$ tahun) atau 1 tumbukan dalam $2,2 \times 10^{5}$ tahun dengan populasi asteroid dekat-Bumi untuk $H<18$. Jumlah sampel dalam penelitian ini yang $\sim 29 \times$ lebih banyak daripada jumlah sampel dalam Gladman dkk. (2000) memang dapat memperbaiki nilai statistik tumbukan asteroid dan planet, namun penggunakan sampel yang lebih besar tidak menjamin dapat memperhalus variabilitas nilai laju tumbukan yang merentang lebar (Rumpf dkk., 2016)[17]. Hal ini karena hasil pengamatan terbaru selain dapat menambah potensi tumbukan dengan menghadirkan objek baru di dalam sampel, juga dapat mereduksi laju tumbukan manakala berhasil mengkonfirmasi potensi tumbukan yang sebelumnya dianggap nyata menjadi tereliminasi berkat adanya perbaikan kualitas orbit melalui data pengamatan yang bertambah. Dengan pertimbangan bahwa kriteria kualitas orbit sampel asteroid tidak dinyatakan secara eksplisit dalam Gladman dkk. (2000)[5], faktor ini dapat menjadi pembeda untuk hasil yang diperoleh sebagaimana ditunjukkan di atas.

Hasil yang didapatkan dalam penelitian ini lebih dekat dengan perolehan Galiazzo dkk. (2016)
$[18,19,20]$ yang mensimulasikan orbit 29 orbit 29 asteroid dekat-Bumi tipe V (asteroid dengan material permukaan basaltik) beserta hasil kloningnya (total berjumlah 1450 sampel) selama $10^{7}$ tahun ke depan. Menggunakan model Tata Surya yang menyertakan Matahari dan kedelapan planet beserta Bulan, Galiazzo dkk. (2016) memperoleh 42 kejadian asteroid menumbuk Bumi. Sebesar 90,6\% sampel yang digunakan mengalami papasan dekat di jarak kurang dari 0,0025 sa (jarak rata-rata Bumi - Bulan). Dari jumlah tumbukan yang terjadi yang diperoleh langsung dari simulasi, diperoleh frekuensi tumbukan dengan planet Bumi sebesar 1 tumbukan tiap $\sim 12$ juta tahun (atau tiap 12.400 tahun untuk populasi asteroid dekat -Bumi dengan $H<18$ ).

\section{Simpulan}

Dari peluruhan 3372 sampel asteroid dekat -Bumi yang terseleksi berdasarkan kualitas orbit terbaik, telah diperoleh fluks masuk populasi kelompok asteroid ini ke zona pembuangan sebesar $14 \pm 2$ asteroid per juta tahun. Dari sejumlah di atas, diestimasi terdapat 1 kejadian tumbukan asteroid dengan planet Bumi dalam kurun waktu $10^{7}$ tahun atau 1 peristiwa dalam 11.000 tahun untuk populasi asteroid dekat -Bumi dengan $H<18$.

\section{Ucapan Terima Kasih}

Penelitian ini didanai oleh Kementerian 
Riset, Teknologi, dan Pendidikan Tinggi Republik Indonesia dengan kontrak bernomor 171A/UN40.D/ PP/2019.

\section{Referensi}

1. Zappala, V., et al. 1996. Phisical and dynamical properties of asteroid families. Italia. Instituto Nazionale di Astrofisica.

2. Bottke, W.F., Vokrouhlický, D., Rubincam, D. P. and Nesvorný, D. 2006. The Yarkovsky and YORP effects: implications for asteroid dynamics. Annu. Rev. Earth Planet. Sci., 34, 157-191.

3. Michel, P., Zappalà, V., Cellino, A. and Tanga, P. 2000. Estimated abundance of atens and asteroids evolving on orbits between earth and sun. Icarus, 143, 421-424.

4. Bottke, W.F., Morbidelli, A., Jedicke, R., Petit, J.M., Levison, H.F., Michel, P. and Metcalfe, T.S. 2002. Debiased orbital and absolute magnitude distribution of the nearEarth objects. Icarus, 156, 399-433.

5. Gladman, B., Michel, P. and Froeschlé, C. 2000. The near-earth object population. Icarus, 146, 176189.

6. Bottke, W.F., et al. 2016. Massive impact-induced release of carbon and sulfur gases in the early earth's atmosphere. Earth and Planetary
7. Kowalski, A., et al. 2008. The Size Distributions of Asteroid Families in the SDSS Moving Object Catalog 4. Icarus 198, 138-155.

8. Brown, P.G., et al., 2013. A 500kiloton airburst over Chelyabinsk and and enhanced hazard from small impactors. Nature 503, 238-241.

9. Popova, O.P., et al. 2013. Chelyabinsk airburst, damage assessment, meteorite recovery, and characterization. Science 342, 1069 1073.

10. Wiśniowski, T. and Rickman, H. 2013. Fast geometric method for calculating accurate minimum orbit intersection distances. Acta Astronomica, 63, 293-307.

11. Wisdom J. and Holman M. 1991. Symplectic Maps for the N-Body Problem. Cambridge. Astronomical Jurnal.

12. JeongAhn, Y., Malhotra, R. 2015. The current impact flux on Mars and its seasonal variation. Icarus, 262:140153.

13. JeongAhn, Y., Malhotra, R. 2017. Simplified derivation of the collision probability of two objects in independent Keplerian orbits, AJ 153, article id. 235, 11.

14. Rickman., et al. 2017. Cometary Imbact Rates on the Moon and Planets during the late Heavy Bombardment. A\&A Volume 598. 
15. Galad, A., et al. 2005. Probability of Subkilometer Asteroids with the Earth. Contrib. Astron. Obs. Skalnat'e Pleso 35, 65-75.

16. Rumpf, C. Et al., 2016. On the Influence of Impact Effect Modelling for Global Asteroid Impact Risk Distribution. Acta Astronautica Volume 123.

17. Morais, M.H.M. and Morbidelli, A. 2002. The population of nearearth asteroids in coorbital motion with the earth. Icarus, 160, 1-9

18. Galiazzo, M. A., Bazso, A., Dvorak, R. 2014. The Hungaria Asteroids: Close Encounters and Impacts with Terrestrial Planets. Mem. Soc. Astron. Italiana, 26, 38.

19. Utama, Judhistira Aria., et al. 2017. Estimasi Rasio Populasi Asteroid Pelintas Orbit Bumi dari Simulasi Orbital yang Menyertakan Efek Termal. Bandung. Prosiding Seminar Nasional Sains Antariksa.

20. Utama, Judhistira Aria., et al. 2019. Steady State Scenario in Asteroids Orbital Simulation with Yarkovsky Effect Inclusion. Indonesia. Jurnal oh Physics : Conference Series. 